Dames de Lettres

Romanistische Abhandlungen 5 


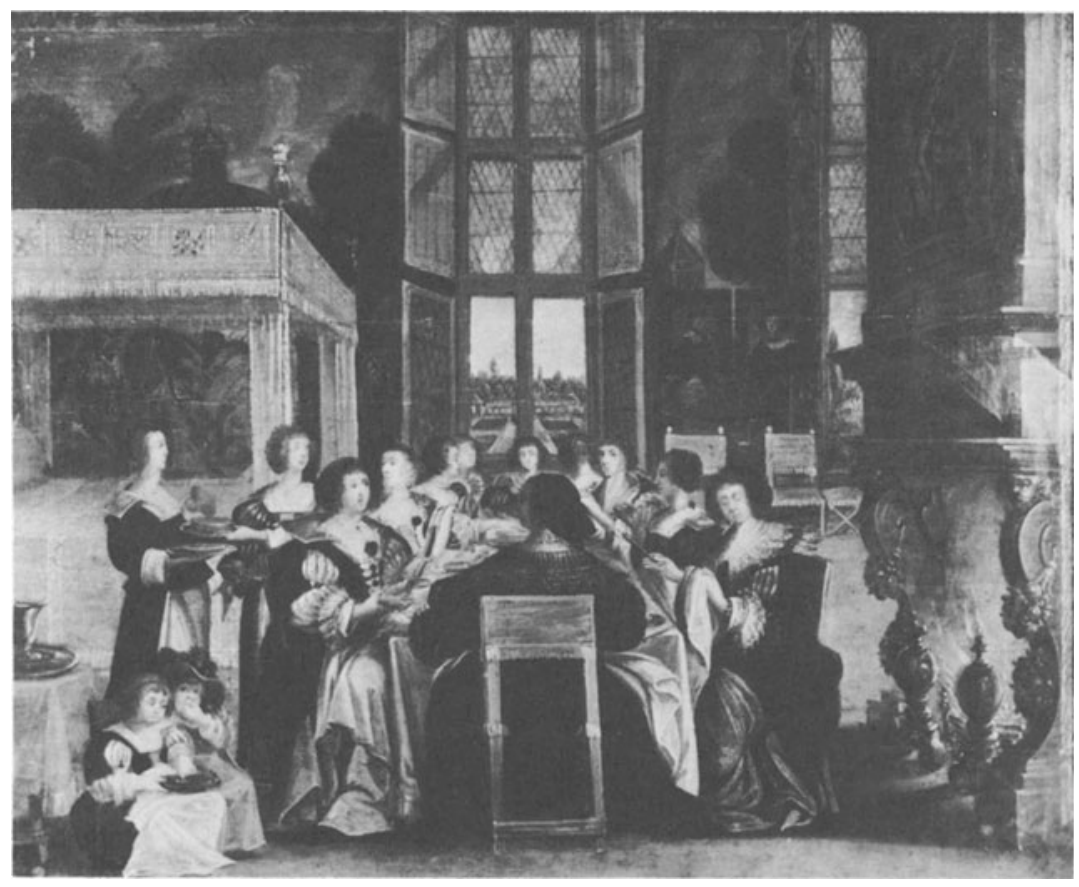

Abraham BOSSE, Les femmes à table en l'absence de leurs maris 
Renate Baader

\section{Dames de Lettres}

Autorinnen des preziösen, hocharistokratischen und »modernen « Salons (1649-1698):

Mlle de Scudéry - Mlle de Montpensier Mme d'Aulnoy

Mit 21 Abbildungen

J. B. Metzlersche Verlagsbuchhandlung Stuttgart 
CIP-Kurztitelaufnahme der Deutschen Bibliothek

Baader, Renate:

Dames de lettres: Autorinnen d. preziösen,

hocharistokrat. u. »modernen « Salons (1649-1698):

Mlle de Scudéry - Mlle de Montpensier - Mme d'Aulnoy /

Renate Baader. - Stuttgart: Metzler, 1986

(Romanistische Abhandlungen; 5)

NE: GT

ISBN 978-3-476-00609-7

ISBN 978-3-476-03236-2 (eBook)

DOI 10.1007/978-3-476-03236-2

C 1986 Springer-Verlag GmbH Deutschland

Ursprünglich erschienen bei J. B. Metzlersche Verlagsbuchhandlung und Carl Ernst Poeschel Verlag GmbH in Stuttgart 1986 
Marguerite Madeleine Stechern

Hans Robert Jauß

und dem Andenken meines Vaters, Alfred Hitze,

in Dankbarkeit gewidmet 
Habent sua fata libelli. Dieses Buch schuldet sein Entstehen und seine Vollendung der über die Jahre wirksamen Unterstützung einer Reihe von Menschen, die an das Thema und die Bearbeiterin glaubten.

Hans Mayer, Dietmar Rieger, Jürgen v. Stackelberg und Karlheinz Stierle haben als auswärtige Gutachter dazu beigetragen, daß die Deutsche Forschungsgemeinschaft mir ein zweijähriges, später um fünf Monate verlängertes Forschungsstipendium gewährte. Der Minister für Wissenschaft und Forschung des Landes Nordrhein-Westfalen hat mich, zur Wahrnehmung dieses Stipendiums, von meinen Dienstpflichten freigestellt.

Die wissenschaftliche Bestätigung erfuhr ich an der philosophischen Fakultät der Universität des Saarlandes, die im Dezember 1983 die Untersuchung als Habilitationsschrift annahm und mich 1984 habilitierte. Hans-Jörg Neuschäfer hat nicht erst zu diesem Zeitpunkt mit seinem fachlichen Rat und Engagement sich meiner Arbeit angenommen. Schon 1977 hatte er mich dazu ermutigt, dieses große Thema anzugehen und ist fortan nie müde geworden, in Phasen der Ermattung oder auftauchender Schwierigkeiten mir mit wissenschaftlicher und menschlicher Unterstützung den Weg zu weisen. Hans Robert Jauß hat mir bei der Endredaktion des Manuskripts mit wertvollem Rat und geduldigem $\mathrm{Zu}$ spruch beigestanden. Erst im Dialog mit ihm fand die Studie ihr jetziges Gesicht.

Sigrid Baudisch hatte bei ihrer bibliothekarischen Tätigkeit mein Thema regelmäßig im Auge und gab mir kostbare Hinweise. Maria Neubauer schließlich war mit der maschinenschriftlichen Manuskripterstellung nicht selten bis zur Grenze des Zumutbaren belastet.

Jedem einzelnen von den Genannten gilt mein aufrichtiger Dank. 


\title{
Inhalt
}

\section{Vorwort:}

$\mathrm{Zu}$ Forschungsstand und Problemstellung..... 1

\author{
Erster Teil: Feudalismus und
}

Frauenkultur im Grand Siècle ................ 19

I. Zwischen Tridentinum und Aufklärung:

»Condition féminine« und elitäre weibliche Praxis 21

1. Die Stellung der Frau im Kirchen- und im Zivilrecht ...... 22

2. Der nachtridentinische Bildungsimpuls und der Beginn

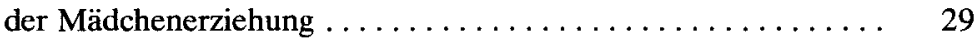

2.1. Von den »petites écoles $z u$ den Frauenorden ............. 29

2.2. Vom Cartesianismus zur Frauenapologie: Poullain de la Barre .. 36

2.3. Von der pädagogischen Reform zum scheinbaren Reformismus:

Mme de Maintenon ..................... 37

2.4. Von der »modernen " Erfahrung zur nostalgischen Evokation:

Mme de Lambert . . . . .................... 40

II. Spiel und Ernst der Frauenbildung

in der Salonkultur 44

1. »Jeux d'esprit « und »bel esprit« $\ldots \ldots \ldots \ldots \ldots \ldots \ldots \ldots .44$

1.1. Geselligkeit und Kultur im Hôtel de Rambouillet .......... . 44

1.2. Die »Maison des Ieux

1.3. Vom »cabinet $z$ um »salon«: Moden der Improvisation ....... 49

1.4. Die »Astrée « als dramaturgisches Brevier .............. 52

1.5. »Bel esprit« und mündliche Dichtung in De Pures

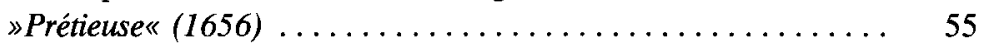

1.6. Literarisches Spiel in den preziösen Zirkeln ........... 57

2. Die gesellige Wissenschaft $\ldots \ldots \ldots \ldots \ldots \ldots \ldots \ldots \ldots \ldots, 61$

2.1. Die Damen und ihre Lehrer ................ 61 
2.2. Die Cartesianerinnen $\ldots \ldots \ldots \ldots \ldots \ldots \ldots \ldots \ldots \ldots . \ldots \ldots$

2.3. Die Lektüren der Mme de Sévigné ................ 64

2.4. Weibliche Bildung und »bienséance «.............. 66

2.5. Die Frauenkultur des Salons und der »moderne« Antihumanismus ....................... 67

\section{Zweiter Teil:}

Von der Mündlichkeit zur Mündigkeit:

Die Frauen und die »Genres Salonniers« ..... 69

I. Unterhaltung und Parteilichkeit:

Mlle de Scudérys »Le Grand Cyrus« (1649-1653)

und $\gg$ Clelie« (1654-1660)

1. Vom geselligen Spiel zur Chronik der Geselligkeit:

Mlle de Scudéry und ihre literarischen Verfahren ........ 73

1.1. Die Salonautorin und die Gelehrten ............... 73

1.1.1. Vom Symposion der Weisen zur preziösen »Feste galante « . . 73

1.1.2. Die Replik der Wissenschaft:

Die Scudéry-Romane in der literarhistorischen Rezeption . . . 75

1.2. Spiel im Roman und Roman als Spiel:

Verschlüsselung als Rätsel im »Grand Cyrus «.......... 77

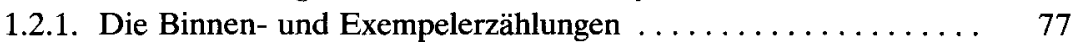

1.2.2. Verschlüsseln und Verewigen $\ldots \ldots \ldots \ldots \ldots \ldots \ldots \ldots$

1.3. Die literarische Abbildung: Die Formen des "portrait moral « .. 81

1.3.1. Die Traditionen des literarischen Portraits ............. 81

1.3.2. Erinna und das Ende der »lys \& roses«:

Die Absage an das »portrait galant « . . . . . . . . . 85

1.3.3. "portrait à clef« und »caractère«:

Huldigung und psychomoralische Distinktion .......... 88

1.3.4. "portrait d'autrui « oder »autoportrait«:

Der » Rahmen« der geschlossenen Form . . . . . . . . . 89

1.4. Gespräche und Gesprächsspiele in der »Clelie« ........... 92

2. Die preziöse Sappho: »Code tendre « und »code galant« ..... 95

2.1. Mlle de Scudéry in der Preziösenkritik und »préciosité«-Forschung .................. 97

2.2. »Le Grand Cyrus « und das Vorbild der Legenden . . . . . . . . . 99 
2.2.1. Von Sappho zu »Sapho«: Die biographischen Korrespondenzen

2.2.2. Die Märchen von der Venusinsel:

Schönheit, Freundschaft und vollkommenes Lieben . . . . . . 100

2.2.3. Die französische Wirklichkeit: Konvenienzehe und Misogamie . . 104

2.2.4. Die aufgeklärten Kelten:

Freie Gattenwahl und religiöse Toleranz . .......... 107

2.2.5. Voraussetzungen des preziösen Fortschritts:

Sappho und die Erziehung der Geschlechter ........... 109

2.3. »Clelie« und die aufgeklärte Kasuistik .............. 115

2.3.1. "Amour parfaite « und "amitié tendre « . . . . . . . . . . 115

2.3.2. Das Ethos der »tendresse " und die weltliche Ehre ......... 119

2.3.3. Sklavin und Herrin: Der preziöse Frauendienst .......... 124

2.3.4. Der »code tendre« und die Utopie einer besseren Gesellschaft . 126

II. Mlle de Montpensier und die literarische Ikonographie der Feudalaristokratie (1659) ..... 132

1. Bauen - Spielen - Schreiben: Kultur als »divertissement « . . . 134

2. Die Divers portraits $(1659) \ldots \ldots \ldots \ldots \ldots \ldots \ldots \ldots \ldots \ldots$

2.1. Das Portrait im geselligen Dialog ................ 140

2.2. Aufrichtigkeit und emblematische Verweisung:

Neue Wege des Portraitierens .................. 143

2.3. Manier und Experiment:

Die Portraitverfahren von Mlle de Montpensier .......... 147

2.4. Das bourbonische Bewußtsein:

Selbstverständnis und Sicht der Welt .............. 151

2.5. Die Offnung des Kreises: Das Portrait in Reprise und Replik . . 154

3. Die satirische Antwort auf Mlle de Scudéry:

Die Portraits in der Princesse de Paphlagonie (1659) . . . . . . 156

\section{Portraitistin oder Modell: Die Frauen} in den literarischen Galerien von $1659 \ldots \ldots \ldots .159$

1. Der Recueil des portraits et éloges . . . . . . . . . . . 159

1.1. Portraitierte, Portraitisten und die Formen des Portraits:

Ein Vergleich beider Bände .......................... 159

1.2. Das »Labyrinth « des »Recueil«:

Entstehungsgeschichte und Autoren ............... 162

1.3. Vom »salon « zum »cabinet«: Die Rückkehr zur Rhetorik ..... 165 
2. Das weibliche Ich: Das Selbstportrait der Aristokratin und die männliche Frauenapologie $\ldots \ldots \ldots \ldots \ldots \ldots \ldots .6167$

2.1. Zur Gattungsbestimmung des Selbstportraits .......... 167

2.2. Tugendkanon und Selbstverständnis in der geschlechtsspezifischen Differenz ............. 168

2.3. Die Aufwertung der Frau in der männlichen Traktatliteratur

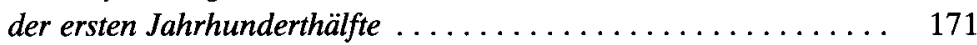

2.4. Die weibliche Selbstaussage und Replik ............. 175

IV. Der Hof und das Exil der Spiele: Mlle de Scudérys Novellen $(1661-1669)$....... 183

1. Celinte (1661): Selbstzitat und Neuorientierung $\ldots \ldots \ldots \ldots 183$

1.1. Ein sentimentaler Kasus im höfischen Rahmen ........... 183

1.2. Von der Neugier zum Hofbericht ............... 185

2. Mathilde (1667): Avignon und die verbannte Geselligkeit . . . 187

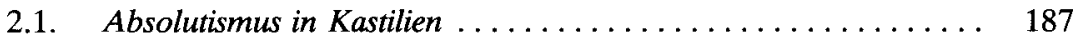

2.2. Vaucluse als $»$ Cour d'Amour $\ll$ und politischer Fluchtraum . . . . 187

2.3. »Les Jeux « als Vorwort und Rahmen ............... 190

3. La promenade de Versailles (1669):

Das Märchen vom guten König . . . . . . . . . . . . . . 193

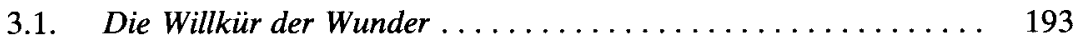

3.2. Der Fürstenspiegel für den aufgeklärten Monarchen .......... 195

3.3. Die höfische Prunkbeschreibung ................ 196

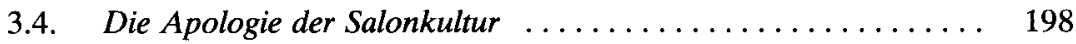

V. Mme de Sablé und die weibliche Maximenkritik $(1659-1663) \ldots \ldots \ldots \ldots \ldots \ldots \ldots \ldots \ldots \ldots \ldots . \ldots 202$

1. Der Salon in Port-Royal: Die Gäste und die Themen . . . . . . 202

2. Mme de Sablé als Mittlerin und Autorin $\ldots \ldots \ldots \ldots \ldots 203$

3. Offenheit und Öffentlichkeit der Maximen La Rochefoucaulds . 207

4. Die Urteilsbildung der Freunde und das Unverständnis

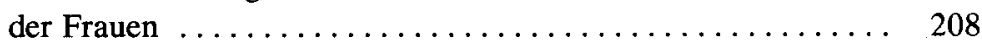


VI. Das Vermächtnis an die »Modernes «:

Mlle de Scudérys »Conversations « und »Entretiens« (1680-1692)

1. Die "modernen « Autorinnen und die Apotheose

der »Sapho nouvelle«: Mlle de Scudéry im Antikestreit

2. Von der »Morale du monde « zur moralischen Welt:

Die Lehrgespräche

3. Funktion und Beteiligung der Geschlechter bei den Gesprächen

4. Die Verteidigung des neuzeitlichen Fortschritts und die aufklärerische Hoffnung

\section{Mme d'Aulnoy und das feminine Salonmärchen} (1697-1698)

1. "Féerie « und »modernes « Mittelalter

1.1. Die Märchenmode und ihre Voraussetzungen

1.2. Die »moderne Bedrohung des Fortschritts:

Perrault und die Moral der »mulier domestica"

1.3. »Bagatelle«, »broderie«, »badinage«:

Die Ästhetik des weiblichen Märchens

1.4. Die »contes de fées" in der Literaturgeschichte und -kritik . . . . 236

2. Mme d'Aulnoy und ihre Quellen ............... 239

2.1. Die Tradition des Volksmärchens: Mme d'Aulnoy im Lichte der Märchenforschung und Märchenpsychologie .............

2.2. Die Anverwandlung der literarischen Vorlagen und des barocken Gesamtkunstwerks .................... 244

2.2.1. Der Rückgriff auf das Mittelalter ................ 244

2.2.2. La Fontaine und der Stoff von Amor und Psyche .......... 246

2.2.3. Die Wunder des höfischen Barock in der Prunkbeschreibung: Feste - Grotte - Ballett

2.2.4. Das Verhältnis zu Straparola und Basile ............... 259

2.2.5. Die Salongattungen und die preziöse Tradition ........... 261

2.2.6. Die Affen und die Leidenschaften: Die Racine-Parodie ... . . . 264

3. Psyches Erlösung:

Das Feenmärchen als weibliche Glücksdichtung . . . . . . 267

3.1. Dämonenverschreibung und Opferung: Die Zwangsverheiratung . 267 
3.2. Vom Tierbräutigung zum Wunschgeliebten:

Die märchenhafte Metamorphose des Mannes . . . . . . . . . . 269

3.3. Die Wunderdinge der Feen und die Entdeckung der Frau . . . . 270

3.4. Das Umspielen der »bienséance«: Die Frau im Männergewand .. 273

3.5. Vom Hof zur arkadischen Freiheit: Der utopische Lebensraum . . 275

\section{Nachwort und Ausblick: Von der »weiblichen «} zur »männlichen « Aufklärung

Anmerkungen $\ldots \ldots \ldots \ldots \ldots \ldots \ldots \ldots \ldots \ldots \ldots \ldots \ldots$

Vorwort: Zu Forschungsstand und Problemstellung ... 286

\section{Erster Teil: Feudalismus und Frauenkultur}

im Grand Siècle ............................... 287

1. Zwischen Tridentinum und Aufklärung:

»Condition féminine« und elitäre weibliche Praxis . . . . . . . 287

II. Spiel und Ernst der Frauenbildung in der Salonkultur . . . . . . . 289

\section{Zweiter Teil: Von der Mündlichkeit zur Mündigkeit:}

Die Frauen und die »Genres Salonniers« ............ 294

I. Unterhaltung und Parteilichkeit. Mlle de Scudéry:

Le Grand Cyrus (1649-1653) und Clelie (1654-1660) . . . . . 294

1. Vom geselligen Spiel zur Chronik der Geselligkeit:

Mlle de Scudéry und ihre literarischen Verfahren . . . . . . . . 294

2. Die preziöse Sappho: »Code tendre« und »code galant « . . . . . . 298

II. Mlle de Montpensier und die literarische Ikonographie

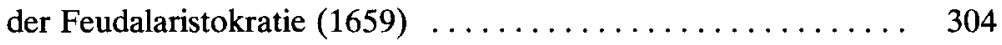

III. Portraitistin oder Modell:

Die Frauen in den literarischen Galerien von $1659 \ldots \ldots \ldots . .307$

IV. Der Hof und das Exil der Spiele:

Mlle de Scudérys Novellen $(1661-1669) \ldots \ldots \ldots \ldots \ldots \ldots$

V. Mme de Sablé und die weibliche Maximenkritik (1659-1663) .. 311 
VI. Das Vermächtnis an die »Modernes«:

Mlle de Scudérys Conversations und Entretiens (1680-1692) . . 313

VII. Mme d'Aulnoy und das feminine Salonmärchen (1697-1698) . . 315

Literaturverzeichnis ................... 322

1. Verzeichnis der Abkürzungen $\ldots \ldots \ldots \ldots \ldots \ldots \ldots \ldots \ldots, 322$

2. Die femininen Texte $\ldots \ldots \ldots \ldots \ldots \ldots \ldots \ldots \ldots \ldots \ldots \ldots$

3. Quellen und Dokumentation bis $1800 \ldots \ldots \ldots \ldots \ldots \ldots . \ldots 324$

4. Forschung und Literaturkritik ab $1800 \ldots \ldots \ldots \ldots \ldots \ldots$

Namensregister ...................... 346

Verzeichnis der Abbildungen .................. 355 


\section{Vorwort: Zu Forschungsstand und Problemstellung}

Wenn es im 16. Jahrhundert darum ging, in der »Querelle des femmes « dem misogynen Diskurs zu begegnen, so war es der Mann, den es reizte, im Paradoxon die faktische und die postulierte Inferiorität der Frau mit brillanter Gelehrsamkeit ins Gegenteil zu verkehren (Cornelius Agrippa ab Nettesheim, Jean Bouchet, François de Billon, Guillaume Postel). Allein Marie de Romieu (1581) stimmt in den Chor derer ein, die für das weibliche Geschlecht den Vorrang über das männliche beanspruchen. Bereits Marie de Gournay (1622) scheint die Unverbindlichkeit des rhetorischen mundus inversus erkannt zu haben, denn, wie die meisten Schriftstellerinnen nach ihr, plädiert sie für die Gleichwertigkeit von Mann und Frau. [1] Gleichwohl sind die Apologeten nicht allein als ritterliche Sprecher eines zum Schweigen verurteilten Geschlechts anzusehen. Zum einen mindert das Vergnügen an der Schwierigkeit, eine derart verlorene Sache beweiskräftig zu verteidigen, den Eindruck von großmütiger Selbstverleugnung, zum anderen gibt es bereits eine Reihe von Dichterinnen und Erzählerinnen, über die sich weibliches Bewußtsein in der Renaissance zumindest in Ansätzen mitteilt. »Diana oder Lukretia? « betitelt E. Sullerot das ihnen gewidmete Kapitel ihrer Histoire et mythologie de l'amour, doch die schreibenden unter den Frauen des 16. Jahrhunderts sind gemeinhin alles andere als bereit, den an Griseldis (Lukretia) orientierten Frauenspiegel und Tugendkodex auf sich zu beziehen. Sie entdecken und besingen die als schicksalhaft begriffene Leidenschaft, die Schönheit des eigenen und des männlichen Körpers, und sie fürchten das Alter, weil es Lust und Sinnlichkeit ausschließen wird. [2]

Gewiß, Olympe Liébaut antwortete auf Desportes' Stances de mariage mit den Misères de la femme mariée, einer Reihe gereimter Kurzportraits tyrannischer Gatten und ihrer Opfer. Marguerite de Navarre läßt eine Ehefrau, die die Untreue des Gatten in gleicher Münze heimzahlt, sich mit dem Anspruch auf Gleichheit der Gesetze und der Ehrzumessung rechtfertigen. Verharrt dabei die eine, wie Hélisenne de Crenne oder Jeanne Flore, im exemplarischen Cliché der »disconvenance des mariés«, so nimmt die andere wiederum mit der Verurteilung der »devisants « dem Aufbegehren jede Legitimation. [3]

Erst im folgenden Jahrhundert wurde es den Frauen möglich, weiterreichende Fragen zu stellen, im Gespräch freilich mit dem Mann, der sie zu formulieren half. I. Maclean beschreibt die erste Jahrhunderthälfte als Weg zur Woman triumphant, C. C. Lougee als den zum Paradis des femmes. Nachtridentinischer Marianismus, weibliche Regentschaften und der weltlich-gesellige und christliche Heroinenkult, dazu das gewandelte Frauenbild der Literatur, der Erziehungstraktate und des preziösen Salons sind für den einen wie für die andere die Anhaltspunkte dafür, daß nun die »Querelle des femmes« endgültig zugunsten der 
Frauen entschieden war. Dabei ist die Beschränkung auf das, was M. Albistur und D. Armogathe »le féminisme élitaire " [4] nennen, offensichtlich.

In der Tat war, angesichts des allein in dieser Schicht relativ geringen Bildungsgefälles der Geschlechter, nur bei den Frauen des Adels und hohen Bürgertums zu erwarten, daß sie der Widersprüche bewußt werden konnten, die nicht zuletzt durch die Neufassung der sie betreffenden tridentinischen Canones verstärkt zutage traten. Erst in der jüngeren historisch-soziologischen oder kirchen- und rechtsgeschichtlichen Forschung (P. Chaunu, A. Lottin, R. Mousnier, F. Lebrun, J.-L. Flandrin, J. Gaudemet u.a.) zeichnen sich die Rahmenbedingungen weiblichen Bewußtwerdens und Schreibens und damit dessen zu erwartende Gegenstände ab. Diese aber lassen die summarischen Überblicke zur »Geschichte der Frau « (A. Decaux, M. Bardèche) zwangsläufig ebenso unberücksichtigt wie die allein auf literarische Belege gestützten Arbeiten von F. Baumal, G. Fagniez, C. C. Lougee und letztlich auch I. Maclean.

Wenn diesen allen auch das Interesse an den Voraussetzungen einer Kultur zuzugestehen ist, die weitgehend von den Frauen bestimmt war, so stellen sie doch die Frage nach den Inhalten femininer Selbstbesinnung und den Formen, in denen diese sich - nicht allein, aber doch vor allem - literarisch niederschlug, nicht. Dies gilt insbesondere auch für die Untersuchungen, die der Salongeselligkeit gewidmet sind. M. Magendie hatte diese als Brennpunkt der das Grand siècle charakterisierenden "politesse mondaine « beschrieben, und die ihm weitgehend verpflichtete - und unvollendete - Studie von $R$. Lathuillère führte, trotz der thematischen Eingrenzung auf das Preziösentum, in dieser Hinsicht ebensowenig weiter wie die eher essayistisch-deskriptiven Darstellungen von R. Picard und G. Mongrédien.

Zum einen verstellte diesen gelehrten Nachfahren der Französischen Revolution ein unreflektiertes ständisches Credo den Blick für das fortwährende Vergeistigungsstreben und den hohen ideellen Anspruch des alten Adels, der zwischen Bürgertum und zentralistischem Absolutismus zerrieben zu werden drohte. Zum anderen hatten sie Aufmerksamkeit und Verständnis für jene gesellige Gesellschaft auch in bezug darauf verloren, wie in ihr die Frauen im Schutz der bewußt und offensiv erneuerten Chevalerie als einzelne oder als Gemeinschaft zum Sprechen und Schreiben fanden. Wie der Salon als Institution dem bedrängten Stand ein Refugium war, so eröffneten ihm die dort gepflegten Formen kunstvoll ritualisierter Konversation und der zwanglosen literarischen Improvisation der Gesprächsspiele Möglichkeiten der Abgrenzung zum Bürgertum der Schreiber und Schriftsteller, der Gelehrten und Humanisten. Diese "jeux d'esprit« allererst sind es, die die Frauen der Salons von Beargwöhnungen und Zwängen befreiten, die einer literarischen Betätigung ihres Standes und mehr noch ihres Geschlechts nahezu formelhaft assoziiert wurden.

Der literarhistorische Kanon hingegen verblieb im Bann der - im Salon freilich geächteten - humanistischen Erudition und einer normativen Poetik, die mit dem Universalismus des Klassischen und der in ihm begründeten Ästhetik der »Meisterwerke« die bürgerliche Wissenschaft nicht anders zu nobilitieren ver- 
hieß als zuvor die »Anciens« des 17. Jahrhunderts. Es nimmt darum nicht wunder, daß dem ewa von $M$. Magendie und $R$. Lathuillère durchaus registrierten Handbuch von Ch. Sorel, La maison des ieux (1642), ebensowenig Bedeutung beigemessen wurde wie den mit ihm offensichtlich initiierten literarischen oder Gesprächsspielen, die G. Mongrédien kurzerhand als »miettes poétiques « abtat. [5] In Analogie dazu haftete dem »bel esprit«, der dieser Geselligkeitskultur sich verschrieben hatte, das Odium effeminierter Unernsthaftigkeit an, gerieten die antiakademischen Ausfälle in De Pures Prétieuse (1656) zusammen mit der Aufwertung (männlicher) momenthafter Brillanz und (weiblicher) von Wissen unbelasteter Plauderkunst in den Verdacht satirischer Karikatur. [6]

Hatte F. Nies am Beispiel der Sévigné-Briefe den aristokratisch-geselligen Hedonismus und das ihn begründende »Haltungsideal des Unernst-Unverbindlichen « dargestellt [7], so stand bislang eine Untersuchung des Gewinns aus, den der Salon als Raum und Rahmen für die Frauen bedeutete: ein Kontinuum der intellektuellen und literarischen Bildung und Kreativität, das über die Mündlichkeit sie mündig werden ließ. Damit ist für diese Arbeit der Horizont neuer Fragen umrissen.

Mit den Zirkelbildungen vom Hôtel de Rambouillet bis zum Salon der Modernisten verfolgt die Studie die in den Wellenbewegungen der Mode einander ablösenden Konversationsspiele und deren Niederschlag in den literarischen Formen, die sich die Damen erschließen: Schlüsselroman oder -erzählung, »portrait mondain«, Maxime, Lehrgespräch und Feenmärchen. Die latente Misogynie mancher »Anciens « (La Bruyère, Boileau u.a.), auf die die Autorinnen antworten, war zuvor den Literarhistorikern ebensowenig zum Problem geworden wie die Kontinuität eines »modernen « Frauenkults, der in der »Chambre bleue « beginnt und über die »Querelle« des Jahrhundertendes an die Aufklärung vermittelt wird. Die von A. Adam [8] geforderte Untersuchung der Frage, inwieweit der Salon der »Modernes« der preziösen Vergangenheit verhaftet ist, war noch immer ein Desiderat.

In der bisherigen wissenschaftlichen Behandlung der "préciosité « ist das Scudérysche Oeuvre allenfalls isoliert betrachtet worden. Damit blieben das Widerspiel von (gelebter) Literatur und (literarischem) Leben, das dieses spiegelt, die wechselnden Übergänge von Mündlichkeit und Schriftlichkeit, die progressive Vermittlung von Lektüre (Rosenroman, Astrée, Amadis), kollektiver Improvisation (die erotische Topographie des "Tendre «) und Verdichtung im geschriebenen Text (Clelie) gleichermaßen verborgen. Unbekannt war die Vorarbeit der Autorin für die Entstehung der Maximen und »maximes d'amour «, für die Kunst des Portraitierens und das liebes- und moralkasuistische Raffinement (»anatomie du coeur«), das dies Jahrhundert der Affektendebatte auszeichnet. In welchem Maße sie und ihr Werk zum Angelpunkt einer Einheit von Preziösentum und Modernismus wurde, konnte ebensowenig bemerkt werden. Komplementär zur traditionellen Darstellung des Grand Siècle tritt hier nun ein anderer - nicht nur - literarischer Geschmack der Zirkel und ihrer Mitglieder ans Licht. Er reicht von Voiture bis Houdar de la Mothe, von Mlle de Scudéry bis 
Mme d'Aulnoy; von der (affichierten) Mündlichkeit und den frühen »Recueils collectifs « bis zu der des Mercure galant oder von De Vertrons Nouvelle Pandore; von der chiffrierten Chronik bis zum Feenmärchen. Mit der Dichotomie von »salon« und »cabinet «, aristokratischem Spiel und humanistischem Ernst, gerät jene Seite des Diptychons zum ersten Mal zusammenhängend in den Blick, die in einem an Boileau oder Voltaire orientierten Kanon keine vorurteilsfreie Würdigung finden konnte. Im zeitlichen Nacheinander und in der ständischen und ideologischen Besonderheit lassen sich zuletzt auch die Salons selbst in anderer Weise darstellen.

Der Revision bedürftig war zunächst die Gattungsbeschreibung der beiden Scudéry-Romane [9], nachdem bis zu H. Coulet die literarische Kritik nicht bereit oder imstande war, von den - der Autorin im übrigen weitgehend eigenen normklassischen Maßstäben abzurücken und sie dieser damit den vermeintlichen Zerfall der erzählerischen Großform anlasten mußte. Der älteren Forschung galten der Cyrus und die Clelie als Zeugnis für die chiffrierte Lebenswirklichkeit oder als Handbuch geselliger Erziehung. Wenn V. Cousin dabei sein Interesse auf die Schlüssel zu den Portraits konzentrierte, so wandte sich jüngst $\mathbf{A}$. Niderst denen der Haupthandlung und vor allem der Binnenerzählungen zu, doch keiner von ihnen begriff Portrait und »histoire« als »jeux d'esprit«, die, zusammen mit anderen, schriftlich erhaltenen literarischen Spielen, den Roman als Salonchronik, als Epos des 17. Jahrhunderts konstituieren. Hier bewies, wie in der übrigen Scudéry-Kritik, die Barock- und Frauenfeindlichkeit Boileaus über die Jahrhunderte hinweg ihre zählebige Wirksamkeit. Die Häßlichkeit der Autorin, die vermeintliche Unlesbarkeit ihrer Romane und das "Kindische" der bei ihren »Samedis" praktizierten Spiele blieben mit Genugtuung wiederholte Gemeinplätze (Tallemant, Sainte-Beuve, G. Mongrédien, M. Magendie u.a.).

Weder Tingle Keating noch J. Plantié, der die vorzügliche Gesamtdarstellung des »portrait mondain « zu danken ist, erkannte $\mathrm{Ch}$. Sorel als die eigentliche Vorlage der Scudéryschen Portraits: Bereits zwei Jahrzehnte vor J. Plantiés frühestem Beleg empfahl dieser das in Worte gefaßte Menschenbildnis als aufzugebende Spielstrafe. M. Kruse entging Sorels Anregung für ein weiteres Spiel: das »Banquet des sept Sages (Cyrus IX). [10] Die 46 Binnen- und Exempelerzählungen beider Romane, die auf den in ihnen entfalteten preziösen »code tendre « hin zu untersuchen waren, sind in der im übrigen sachdienlichen Untersuchung von R. Godenne hinsichtlich ihrer Funktion innerhalb des Romangefüges beschrieben worden. Eine vorgängige Oralität der Form wurde dabei jedoch ebensowenig zum Problem wie insgesamt die Verwurzelung der Romane in der Salonkultur.

A. Niderst begnügte sich mit der - von J. Plantié teilweise korrigierten - Aufdeckung der durch vielfache Verschränkungen verfremdeten zeitgenössischen Wirklichkeit, ließ aber kompositorische Fragen dabei außer acht. Er verkannte einmal, wie zuvor C. Aragonnès oder R. Picard, die zirkelstiftende Funktion der mythologisch-historischen Camouflage, deren Adressaten damit zu literarischen Subjekten wurden, und zum anderen den Rätselcharakter des Romans selbst, für 
den der vielfach irregeführte Leser als dechiffrierender der Instanz des Autors gleichrangig wird. Das Verwirrspiel der Uneindeutigkeit und Travestie in den verschlüsselten Personen- oder Raumbeschreibungen lie $\beta$ bereits hier die Berührung mit den Allegorien des barocken Gesamtkunstwerks (Gartenlandschaft, Schloßarchitektur, höfisches Fest) erkennen, die in den Portraits im Kreis der Grande Mademoiselle oder dem Feenmärchen des Salons der »Modernes« wiederkehren wird.

J. Plantié ist der Frage nicht nachgegangen, inwieweit die Gleichsetzung weiblicher Schönheit mit der Inferiorität der Frauen in der Humoralpathologie und Physiognomik die Betroffenen provozieren mußte. Mlle de Scudérys Kritik am (männlichen) galanten Portrait und der Unverbindlichkeit einer petrarkistischtopischen Metaphorik (»lys \& roses«), die die Autorin seit dem Cyrus durchgängig und wiederholt mit Voiture assoziiert, und ihr darin begründetes Plädoyer für das den Frauen als literarischen Subjekten angemessenere moralische Abbilden in den Femmes illustres (1642-1644) sind von ihr unbemerkt geblieben. Die Untersuchung des "portrait moral«, das nur als verallgemeinerndes satirische Züge annehmen darf, und der »portraits à clef«, die bisweilen in der verschlüsselten 》Galerie « zusammengefaßt sind, versprachen darüber hinaus aufschlußreiche Informationen zur Vorgeschichte der großen Moralisten. Dasselbe gilt von den zahllosen liebes- und moralkasuistischen Gesprächen, die besonders für die Clelie und deren geselligen Rahmen, die »Samedis«, charakteristisch sind. Die Auswertung dieser Unterhaltungen, die nahezu alle das Jahrhundert beschäftigenden Fragen - von der »raison des bêtes« über die Kunst des Briefeschreibens bis zur Temperamentenlehre - berïhren, blieb auch nach $\mathbf{B}$. Beugnots Hinweis auf die Forschungslücke anhaltendes Desiderat: $\mathrm{Ph}$. Wolfe nahm sich allein - und dies in summarischer Oberflächlichkeit - der später isoliert veröffentlichten Konversationsbände der Autorin an, unterließ dabei jedoch die - dornige - Einbeziehung der Romane und blieb die Antwort auf die Frage von Nachdruck, Umarbeitung oder Neufassung schuldig. [11] Diese war darum in dem den »Entretiens« gewidmeten Kapitel zu geben.

Ebensowenig wie in formaler waren in ideengeschichtlicher Hinsicht Le Grand Cyrus und Clelie hinlänglich und mit der gebotenen Redlichkeit ausgewertet worden. [12] Obwohl sich die Forschung darin einig ist, daß Mlle de Scudéry den vielfach karikierten Sozialtypus der »précieuse « wie keine andere vertritt, ist ihr - von A. Adam über Y. Fukui bis R. Lathuillère - der Vorwurf nicht zu ersparen, daß sie, in unreflektierter Berufung auf die zeitgenössische Preziösenkritik, sich von dem Zerrbild der Satire nicht zu lösen bereit war. Auch W. Zimmer, der diese zum Gegenstand einer umfassenden Untersuchung machte, unterlie $B$ jedes relativierende Urteil oder den Versuch, die psychologischen und sozialen Beweggründe des manifesten Widerstands zu analysieren. Wohl nicht zufällig überlebte auch in der Gegenwart die Berührungsangst gegenüber dem ersten, hier nun detailliert beschriebenen, weiblichen Entwurf einer märchenhaften Utopie. Diese reicht von der Erneuerung geschlechtsspezifischer Leitbilder über die erstmalig und in der Korrektur an den bislang allein männlich besetzten »codes« 
von einer Frau formulierte - andere Liebeskonzeption bis hin zu allgemeineren sozialen und moralischen Postulaten. Die Kritik der Autorin am römischen Recht und der mit ihm legitimierten allein männlichen Verfügungsgewalt über die Frauen, an dem als latent misogyn enthüllten Schönheitskult des neuplatonischen Idealismus, an der versäumten oder verfehlten Mädchenerziehung, die Auseinandersetzung mit der kriegerischen Rhetorik des männlichen »code galant «, der restriktiven weiblichen »bienséance« oder den verstiegenen Deformationen des Preziösentums selbst mußten dabei unbemerkt bleiben. Dasselbe gilt für den nicht minder aufklärerischen Entwurf einer von der tyrannischen Monarchie befreiten Gesellschaft der religiösen Toleranz und der den König beratenden Philosophen, für die zugleich regressive und fortschrittliche Evokation des Amazonenstaats oder der keltischen freien Gattenwahl, die Berührungspunkte des "code tendre " mit Jansenismus oder pythagoreischer Katharsis und zuletzt dessen stufenweise vollzogene Herausforderung an die allgemeingültige Moral.

J.-M. Pelous hat in jüngerer Zeit die beiden »codes« vorbildlich dokumentiert, doch auch ihm verstellen offensichtlich die Vorbehalte angesichts der vermeintlichen Grausamkeit weiblicher Verweigerung, die er »matriarchalischem Imperialismus « assoziiert, den Blick für die Notwendigkeit einer preziösen Kasuistik, die allein in der Märchenlösung die gespaltene weibliche Identität zur Selbstfindung zu führen versprach; den Blick aber auch dafür, daß Mlle de Scudéry mit der Selbstbindung des Mannes auch die Besinnung der Frauen auf neue Werte und Lebensentwürfe gebot und gegenüber den vielfachen Gefährdungen ihres Geschlechts, darunter der Koketterie, der geschwätzigen Oberflächlichkeit oder der spröden »cruauté«, alles andere als verblendet war. Während ihm der »code tendre« erst den »Aufstand der Ungeliebten« hervorzurufen schien, ließ dieser sich vielmehr, im Zusammenhang mit der - bewußten und betroffenen - literarhistorischen Wertung der Renaissancelyrik bei Mlle de Scudéry, als weibliche Antwort auf den »code galant « erweisen.

Auch wo Teilaspekte des Scudéryschen Werks wissenschaftlich rezipiert wurden, geschah diesem als Ganzen gemeinhin Unrecht. Die »Histoire de Sapho« (Cyrus X) etwa wurde - in der Tradition von Boileau, Tallemant und SainteBeuve - von G. Mongrédien, C. Aragonnès oder A. Niderst zum peinlich glorifizierenden Selbstportrait verkürzt, das die physischen Mängel zu tarnen hätte. Die literarische Verpflichtung gegenüber dem - biographisch zu erklärenden Vorbild der 15. Heroide von Ovid wurde indes hier stets übersehen. H. Rüdiger wiederum, der unter anderem die Wirkungsgeschichte der "Sappho Phaoni« verfolgte, entging dieses wichtige Zeugnis des französischen 17 . Jahrhunderts, mit dem in der Tat der (weibliche) Einbruch in eine Rezeptionsgeschichte der Sappholegende vollzogen wurde, die Rüdiger für die Epoche zu Recht als durchweg hämisch beschreibt. [13]

Vergeblich würde man schließlich in den eingangs erwähnten Darstellungen zur Geschichte der Frau, ihrer Erziehung, Bildung und Leitwerte, nach den vielfachen und hierfür unverzichtbaren Stellungnahmen von Mlle de Scudéry zu einem weiteren Problemkomplex suchen: dem des Alterns und, im Zusammen- 
hang damit, des falschen, akzidentellen Werts weiblicher Schönheit, der letztlich dem Selbstverlust der Frauen gleichkommt. Dasselbe gilt für das Verhältnis der Geschlechter selbst und die Scudérysche Ablehnung jener Gleichheit, wie sie von männlichen und weiblichen Frauenapologeten (Poullain de la Barre, Mlle de Gournay u.a.) immer wieder postuliert wurde.

Wenn der literarische Kanon sich einem Werk beharrlich versperrte, das nach der Bibel zu den meistgelesenen des 17. Jahrhunderts gehört, so war um so weniger ein vorurteilsfreies Interesse an der Frage zu erwarten, welche ideologische Entwicklung sich in den beiden monumentalen Romanen selbst vollzogen haben könnte. Die Ablösung der barocken Wunder, der Märchenlösungen und der regressiven Utopien des Cyrus durch die rationalistische, lehrhafte Kasuistik der Clelie ist nicht zufällig. Hier werden die Berührungspunkte der "préciosité « und der Frühaufklärung deutlich. Bezeichnenderweise ist es eine Frau, die dem Ende einer Unterdrückung und Entmündigung das Wort redet, als deren Opfer sie nicht allein ihr Geschlecht begreift. W. Krauss hat schon auf einige der vielfältigen Aspekte der preziösen Bewegung hingewiesen, die in dem verfälschten, an Molières Satire orientierten Bild fehlen mußten. [14] Die Scudéry-Romane lassen nun in der Tat erkennen, in wie hohem Maße das Preziösentum die französische Aufklärung antizipiert.

Während die Scudéry-Romane als integrative Chronik des Hôtel de Rambouillet und der »Samedis « zu deuten sind - Salons, die durch ihre ständische Differenz anders, als bisher gemeinhin angenommen, nicht so sehr voneinander abgegrenzt wie sie durch die Spielkultur verbunden sind -, eröffnet sich mit dem Kreis um Mlle de Montpensier ein neues Beispiel jenes geselligen Zaubers, den die Frondeuse auch ins Exil zu retten verstand. Die Romanhaftigkeit ihrer Existenz, die an die d'Aulnoyschen Märchenprinzessinnen denken läßt, war den Zeitgenossen und Biographen offenbar bewußter als ihr selbst. Ihr scharfer Verstand, dem die »fausse dévotion «, die Unwahrscheinlichkeiten des Barockromans oder unangemessene preziöse Manier gleichermaßen zum Opfer fielen, erinnert an die großen Klassiker des Jahrhunderts. Der Bourbonenstolz, den J. Plantié ihr anlastet, ließ sie zwar verkennen, wie weit das von ihr und Mme de Motteville entworfene erotische Arkadien dem »Royaume de Tendre« der Autorin ähnelt, der sie zur Rivalin werden wollte. Zugleich aber befähigte gerade er sie dazu, das literarische Portrait aus den Fesseln topischer Unverbindlichkeit und dem Odium der Käuflichkeit zu befreien.

Die monumentale Studie von J. Plantié beschreibt die Entwicklung des »portrait mondain « bis zum endenden 17. Jahrhundert in Frankreich. Für dessen Berührungspunkte mit Physiognomik und Temperamentenlehre, mit Topik und Tradition der Malerei und Literatur stellt sie kostbares Material bereit, über das hier ausführlicher berichtet wird, da die maschinenschriftliche Thèse schwer zugänglich ist. Das gleiche gilt für J. Plantiés Ausführungen zu Mlle de Scudéry und Mlle de Montpensier, die im Wettstreit miteinander dem Portrait neue und wirkungsgeschichtlich bedeutsame, der vorangehenden Forschung indes unbekannte Formen eröffnen. Im Rahmen dieser Gattungsgeschichte war jedoch kaum zu 
erwarten, daß die meisterlichen Varianten des literarischen Abbildens bei der Grande Mademoiselle in Verbindung gebracht wurden mit deren übrigen Schriften oder mit der Tradition der »jeux d'esprit «, der sie alle entspringen. Bei dem Vergleich der rivalisierenden Autorinnen wurde von J. Plantié damit auch die Frage nicht gestellt, was es für sie beide als Frauen bedeutet, sich - und dies in so entschieden antagonistischer Weise - dieselben im Salon gepflegten Genres zu erschließen, die für die Schriftstellerinnen der nächsten Generation zu Vorbild oder Herausforderung werden: chiffrierte Verewigung und idealtypischer, erzieherischer Entwurf bei der einen; Ulk, Satire und spöttische Distanz, der »königlich « selbstgewisse Blick derer, der das Urteilen zusteht und die der mythologischen Camouflage nicht bedarf, um die Zeitgeschichte - als anekdotische - zu offenbaren, bei der anderen. Mme de Villedieu etwa, bürgerliche und berufsmäBige Erfolgsautorin der Epoche, steht in ihrer beider Nachfolge, erwirbt mit der verschlüsselten Huldigung einer Scudéry die Gunst der Grande Mademoiselle und damit die Freiheit, wie diese, die konkrete und jüngere Historie selbst zu sentimentalisieren und Anekdote oder galante Hofgeschichte als ganz vorrangig »feminines « Genre an das 18. Jahrhundert zu vermitteln. [15]

Die Verhaftung im normativ-selektiven Kanon des Klassischen versperrte J. Plantié auch den Blick für die Ästhetik des barocken Gesamtkunstwerks, für den fluichtigen Zauber der »divertissements « und der allegorischen Exegese, der das humanistisch-bürgerliche aere perennius ironisch übergeht. Reiterspiel, Devise, »Entrée«, Hofballett und Fest, Gartenlandschaft, Schloßarchitektur, Bühnenmaschinerie und Salonmärchen, Schlüsselroman, Memoiren, Korrespondenz und Portrait - dies alles bildet den Hintergrund der Lebenserfahrungen einer in den Salon exilierten Feudalaristokratie und - über diesen - der bürgerlichen Spielemacher (Voiture, Sarasin, Segrais) und Chronisten (Mlle de Scudéry), die sich, gegen den Hof des Undanks und der Käuflichkeit, deren Fahnen verschrieben haben. Als restaurierende Architektin gab Mlle de Montpensier dieser Kultur den Rahmen. Die Sammlerin füllte ihn mit der Galerie der Gemälde und Portraits, welche sie im literarischen Abbilden und in jenen Memoiren belebte und verewigte, die auch in der Nachwelt sich der Aneignung durch jede bestellte, antifeudalistische Historiographie mit gewollter und spielerischer Unvollständigkeit verweigern.

Die Ansätze neuerer Forschung, die der Grande Mademoiselle für die Baugeschichte oder die Memorialistik des 17. Jahrhunderts gerecht zu werden versuchten [16], führten mit den jeweiligen formspezifischen Fragestellungen nicht weiter als J. Plantiés Würdigung ihrer Portraitkunst. Die schreibende Frau schließlich, die von dem Bewußtsein ihres Geblüts sich herausgefordert fühlen mußte, Tassos Discorso della virtù femminile e donnesca im Sinne der letzteren einzulösen und dies zugleich in einer Weise, die ihr Schreiben als befreiende Kompensation für das vergangene Wirken einsetzte, konnte in keiner dieser Untersuchungen zum Problem werden. Wie für Mlle de Scudéry verwischten sich für diese hochmütige Außenseiterin die Grenzen zwischen Literatur und Leben, und wie die Marquise de Rambouillet suchte sie, im Spiel des Augenblicks die 
seelischen Bewegungen der Anwesenden einem tänzerischen Ritual zu unterwerfen, das den Blick der anderen auf sich gerichtet weiß und zwischen gesellschaftlichem Selbstverlust und selbstverlorener Introspektion den Weg zum Ich zu finden vermag. In ihrem Zirkel und unter ihrer Führung ist dieses Ich allerdings vorwiegend ein weibliches.

Die beiden Sammelbände von 1659, die Divers portraits der Mademoiselle und ihres Kreises und das rivalisierende Buchhändlerprodukt, der Recueil des portraits et éloges, sind in ihrer Entstehungsgeschichte von J. Plantié beschrieben und auf einzelne Unterschiede hin untersucht worden. Wertvoll sind daneben die überzeugenden Vorschläge zur Entschlüsselung einiger anonymer Portraits und die Zuschreibung der poetologisch wichtigen Einleitung des Recueil an SaintÉvremond. $\mathrm{Da}$ die Frage nach Geschlechtsdifferenzen hier gar nicht gestellt wurde, ist allerdings um so erstaunlicher, als sich das moralische »portrait d'autrui « und das Selbstportrait als eindeutig weibliche Gattungen bestimmen lassen und gerade die Feminisierung des ersten im Vergleich mit dem zweiten Band mit Händen zu greifen ist.

Zwei Frauen bringen das gesellige Spiel aus dem Holland des Calvinismus und des »clair-obscur « ins Exil der Mademoiselle, die bald die Mode beherrscht und mit der Vielfalt origineller Abwandlungen ihrem Zirkel, aber auch den - wenigen - Frauen des zweiten Bandes, zum Formimpuls wird. Die Divers portraits sind für eine Geschichte weiblichen Bewußtwerdens insofern von unschätzbarer und bislang nicht registrierter Bedeutung, als im Schutz feudalaristokratischer Sicherheit hier erstmalig eine Gruppe von Frauen zum literarischen Subjekt wird. Die erwartete, von Mlle de Scudéry begonnene und aufgegebene feminine Replik auf den männlichen Schönheitskult und erotischen Diskurs des Petrarkismus und Neuplatonismus, die Enthüllung der Ambivalenz der Galanterie also, wurde hier ebenso geleistet wie die Abgrenzung gegenüber all jenen frauenfeindlichen aber auch apologetischen Traktaten, mit denen seit Jahrhunderten in der »Querelle des femmes« über die Frauen verfügt worden war.

Es ist das Verdienst von I. Maclean, die Entwicklung der männlichen Frauenapologie bis zum 17. Jahrhundert nachgezeichnet zu haben, das von C. C. Lougee, dabei die Verfahren der Aufwertung traditionell negativer weiblicher Eigenschaften (Empfindungsfähigkeit, Irrationalität, Intuition) zu ermitteln. Lougee betonte zugleich die voraufklärerischen Interessen dieser Autoren, die mit der geselligen Nobilitierung durch die verehrte Dame soziale Mobilität im Auge hatten und dem Erbadel zur Bedrohung werden mußten. Darauf antwortete das kollektive Selbstportrait der Frauen des Hochadels, das in beiden Arbeiten unberücksichtigt blieb, mit Widerspruch und Korrektur. Der statistische Vergleich der (wenigen) männlichen und der weiblichen Selbstportraits ergab eine deutliche Differenzierung hinsichtlich der Werte, zu denen man sich jeweils bekannte. $\mathrm{Zu}$ beobachten war daneben die Auseinandersetzung aber auch mit der misogynen Topik der Traktate, in denen mit der phlegmatischen Natur der Frau, den Tugenden der »mulier domestica « oder dem Kodex weiblicher Schönheit die alte Vorstellung des existentiell minderrangigen »mas mutilatus « in verbrämter Form weitergetragen wurde. 
Auch im Portrait eines Dritten behaupten sich die Frauen gegen das männliche "portrait galant «. Nun hatte Mlle de Montpensier, auch hierin fortan meisterliches Vorbild, sich an Mlle de Scudéry zu messen, und die ständische Sicherheit eröffnete ihr Freiheiten des psychologisch-moralischen Abbildens, die der anderen verwehrt waren. Da im Maße der Vertrautheit sich der gesellschaftliche Abstand minderte, da die Úberlegenheit sie vor peinlicher Panegyrik bewahren konnte, waren gerade hier die wegweisenden Schritte zur unverhüllten, liebevollen oder kritischen Entdeckung des vereinzelten und einmaligen menschlichen Gegenübers möglich. M. Gerlach Nielsen, deren statistisch-strukturelle Analyse der Portraits bereits im Ansatz das Ergebnis ideologischer Bedeutungslosigkeit vorwegnahm, verschloß sich diese Perspektive [17]; nicht anders J. Plantié, die mit dem Vergleich von Stand und Geschlecht auch die Auskunft darïber schuldig blieb, ob überhaupt und unter welcher Feder die Gattung sich aus den Fesseln topischer Unaufrichtigkeit und Typologie befreien könne. Die Rückbindung an die Konventionen von Rhetorik und Buchgeschichte (»cabinet«) sollte das kommerzielle Interesse der Verleger des Recueil und die modische Eitelkeit derer befriedigen, denen im »Familienalbum der Grande Mademoiselle (J. Plantié), in der kleinen Gruppe von etwa 30 Wahlverwandten, kein Platz beschieden war. Bedeutete die Offnung der Gattung für jedwede Zirkel und Individuen die verheißungsvolle Teilhabe an einer Mode, die sich ihrerseits spielerisch aus dem gemeinschaftlichen Besitz schriftlicher Traditionen gelöst hatte, so führte sie indes die Frauen, deren betroffene Mitwirkung an der formgeschichtlichen Entwicklung des Portraits für J. Plantié an keiner Stelle zum Problem wird, einen beträchtlichen Schritt zurück. Erneut verwiesen auf die Stilisierungen der männlichen selbstverhafteten Projektion genußvoll erfahrener erotischer Unerfülltheit, verstummen sie - im Recueil - als literarische Subjekte, da für dessen Autorinnen der Salon als Rahmen mündlicher Mündigkeit nur noch ausnahmsweise befreiender und schützender Fluchtraum war.

Der herausfordernde literarische Dialog von Mlle de Montpensier und Mlle de Scudéry findet mit den Novellen der letzteren $(1661,1667$ und 1669) seine Fortsetzung. Die drei Texte wurden jüngst in Nachdruck oder Neuausgabe wieder zugänglich gemacht und von A. Niderst und R. Godenne mit Vorworten versehen, denen nicht vorbehaltlos zuzustimmen ist. [18] A. Niderst wiederholte dabei die Entschlüsselungen aus seiner früheren Scudéry-Monographie, ohne deren Korrekturen durch J. Plantié einzubeziehen. Gegenüber der behaupteten Wende der Autorin zu einem wissenschaftlichen, an La Mothe le Vayer orientierten anticartesianischen Libertinismus gebieten weiterreichende frühere Belege aus Cyrus VIII und Clelie VI, VII und X ebenso große Skepsis wie die sehr nuancierte Auseinandersetzung mit Descartes im Gespräch »De l'incertitude« (1686). Der sich hier behauptende aufklärerische Optimismus, der die Hoffnung auf moralische Selbstbindung und Erneuerung dem scharf kritisierten libertinen Zweifel entgegenhält, wird geteilt von Mme de Sablé und den Damen ihres Salons in Port-Royal, von Saint-Cyr und seiner Stifterin und von allen Frauen schließlich, die in der Nachfolge von Mme de Maintenon als Erzieherinnen zu Schriftstellerinnen werden. 
Eine literarische Würdigung der Celinte - der märchenhaften sentimentalen Wunschwirklichkeit zum einen, der Öffnung zu den »Relations « und damit der galanten Maskierung der historischen Wahrheit im Hofbericht zum anderen wurde von Niderst nicht erbracht. Bei R. Godenne war sie durch Vorurteile der Scudérykritik verstellt. Die in die Mathilde aufgenommenen »Jeux « und das Gespräch zu deren Verteidigung, wahrlich ein Schlüssel zum Gesamtwerk der Autorin, blieben unbeachtet, die Frage nach den Gründen für die Exilierung der Spielkultur und Salongeselligkeit in das Mittelalter der "Cours d'Amour oder das Italien Petrarcas unterblieb. Dasselbe gilt für die neue Hofkritik, die in der Verfremdung den absoluten Monarchen selbst als Dramaturgen höfischer Unaufrichtigkeit enthüllt.

Die verpflichtende Huldigung der früheren Schlüsselportraits gilt in La promenade de Versailles dem König und dem Fürstendienst des Schwertadels (»Cleandre $\ll$ ), dem der Höfling zum aufrichtigen Freund werden kann. B. Bray hatte die Novelle als Beispiel jener dialogischen Formen beschrieben, die den didaktischen Traktat spielerisch ablösten. H.-L. Scheel interessierte an ihr „Versailles als dichterisches Thema und als Symbol « [19], vor allem also die Beschreibung von Palast- und Gartenarchitektur. Der fiktionale Zusammenhang mit dem früheren Werk der Autorin war in diese Fragestellungen nicht einbezogen. Der Rekurs vom aufklärerischen Rationalismus in der Clelie zu der Willkür der Zufälle und jenen märchenhaften Wundern, denen im Absolutismus die Lösung überantwortet ist, wurde damit nicht zum Problem.

Das bewegte Widerspiel von Literatur und Kunst haben für Clelie $\mathrm{X}$ und die verschlüsselte Abbildung von Vaux-le-Vicomte R. Sayce und G. Goebel in allen Stufen und Übergängen nachgezeichnet. Für Mlle de Scudéry war dies eines der kontinuierlichen, in Erzählsituationen eingebundenen »jeux d'esprit«, die sie auch in den Novellen des Alters beibehielt. In der chiffrierten, detailgetreuen Nachzeichnung der Ballettauftritte Saint-Aignans gibt sie der »description à clef « eine neue Variante, die unsere Kenntnisse vom »ballet de cour « durchaus ergänzen. [20] Ballett und Palastarchitektur sind es, in denen die imaginären Wunder der Dichtung und Mythologie Wirklichkeit werden - zu einer Zeit, als der Absolutismus die Geselligkeit der Spiele und der adligen Frauenkultur nur noch in Vergangenheit und Ferne zu projizieren erlaubt, Boileaus 10. Satire und der Unmut seiner Heroen über die Aneignung der Antike durch die preziöse Liebeskasuistik an Boden gewinnen können.

Mit der Aufarbeitung einer Geschichte der »jeux d'esprit« und der mit ihnen mündig werdenden Frauen mußte neues Licht auf den Salon der Mme de Sablé, sowohl auf dessen Bedeutung wie auf die der Gastgeberin, für die Maximen und das Werk La Rochefoucaulds fallen. M. Kruse hatte hier einzuschränken versucht, doch da für sie nicht auszumachen war, wie man die Neigung zu der neuen Mode erklären und wie man die Mitwirkung von Mme de Sablé einschätzen solle [21], war die Frage erneut zu stellen. In Port-Royal war sie, wie zuvor die Marquise de Rambouillet und die Grande Mademoiselle, umgeben von der - nunmehr jansenistisch verdüsterten - Gesellschaft des Frondeadels. Die Ge- 
spräche galten ernsthafteren Themen, doch im Spiel um die Maximen, ihre Entstehung, Lektüre und Úberarbeitung erhielt sich vieles, wenn auch im Briefwechsel aufgehoben, von gemeinschaftlicher Mündlichkeit, Mitteilung und dialogischer Kurzweil. Wie sehr jedoch die kleinen Schriften der Mme de Sablé in Themen und Bekenntnis den Grundanschauungen des preziösen Salons verpflichtet sind, ist in keiner der ihr gewidmeten Arbeiten angedeutet worden. Konsequent vertritt die Autorin - neben der jansenistischen Abkehr vom Theater oder einer auf Molière vordeutenden Kritik an der Medizin - den Glauben an menschliche Bildungsfähigkeit und moralische Selbstbestimmung, und dies gegen die Jansenisten und La Rochefoucauld, dessen Skepsis sie bezeichnenderweise gerade bei einer Maxime über die Freundschaft - mit einer eigenen - entgegentrat. Wie sie im »honnêteté«-Ideal den Weg zu kontrollierter Selbsterkenntis und -korrektur gewiesen sieht, läßt ihr christlicher Tugendoptimismus sie pädagogische Anweisungen aussprechen, die, wie erwähnt, in ein Kontinuum nun beginnender weiblicher Erziehungsliteratur gehören. Diesen teilt sie mit den Damen ihres Kreises, die als Leserinnen La Rochefoucaulds die zweite Gruppe von Frauen darstellen, über die sich Ansätze weiblichen Wertbewußtseins und Bekenntnisses der Nachwelt vermitteln. Obwohl die Briefe, mit denen sie das von dem Autor und Mme de Sablé erbetene Urteil abgeben, leicht zugänglich sind, ist der gemeinschaftliche Dissens zu dem der männlichen Leser und zu La Rochefoucauld allenfalls registriert, nicht aber begründet worden.

Was Mme de Sablé forderte, eine Pädagogik des Lehrgesprächs, hat Mlle de Scudéry mit ihren Konversationsbänden der achtziger Jahre eingelöst. Daß auch Mme de Maintenon den Genres ihrer erzieherischen Schriften die sjeux d'esprit « der eigenen Salonvergangenheit zugrundelegte, schien ihren Monographen keiner Anmerkung würdig. Die - wie erwähnt - kaum rezipierten geselligen Gespräche der Scudéry, in denen sich u.a. kostbare Zeugnisse über den preziösen literarischen Kanon (De la poésie françoise - die Replik auf Boileaus Art poétique) verbargen, trugen in plaudernder Ungelehrtheit die Moral- und Affektenlehre (Plutarch, Montaigne, Descartes) oder andere Bereiche des Wissens nach SaintCyr, wo sie den jungen Mädchen eine Bildungsteilhabe eröffneten, die die Frauen des Salons ihnen erobert hatten. Die Spielkultur war endgültig im Schreiben aufgehoben, doch dieses blieb an die Regeln der Konversation gebunden. Deren emanzipatorischer Wert konnte freilich nicht erkannt werden, solange die Frage nach dem Gewinn für die Frauen nicht gestellt war. Im Gespräch nämlich hat die intellektuelle Selbstbegrenzung des Mannes den neuen ritterlichen Frauendienst des heroischen Romans abgelöst.

Nach der preziösen erotischen Topographie und der Ethik des »Tendre«, die als erzieherischer Entwurf in der Unverbindlichkeit utopischer Idealität oder Uneinlösbarkeit ihre Grenze fanden, bringt Mlle de Scudéry die Wirksamkeit der Salonkultur in die literarische Reihe zurück, aus der sie ihren Anfang nahm. Indem sie sie an das Neuzeitbewußtsein der »Modernes « bindet, sichert sie ihr Úberleben für den Salon der (Früh-)Aufklärung und bezieht in der Geschichte des weiblichen Bildungsfortschritts, den auch ihr zunächst nur der biographische 
Zufall eröffnet hatte, eine Schlüsselstellung. Eine solche wurde ihr von der dezidierten Modernistin, Mlle Lhéritier, nicht aber von der literarischen Kritik zuerkannt. Was die jüngere Autorin gegen Boileaus Héros de romans und die »Anciens « insgesamt als überlegene Leistung der »Sapho nouvelle in Erinnerung rief - die verhüllende Einkleidung der Gegenwart in vielfachen Verschlüsselungen -, war in den Konversationsbänden ebensowenig mehr zu finden wie in der zeitgenössischen gesellschaftlichen Wirklichkeit. Allein in der »Histoire« (de Belinde) - einem der wenigen »jeux d'esprit «, dem sie treu bleibt -, beschwor Mlle de Scudéry, etwa ein halbes Jahrhundert nach den "Samedis « und der Epoche Ludwigs XIII., in der die Geschichte angesiedelt ist, den »code tendre « und das Modell gestufter Formen der Freundschaft und menschlicher Vollendung. Schreibend suchte sie die Erinnerung an das Wertbewußtsein des alten Schwertadels und damit seiner Art der Frauenverehrung lebendig zu erhalten. Zugleich geht diese Rückbestimmung ein in das Bekenntnis zum "modernen « Fortschritt, der für sie und die Frauen an die Geselligkeit der "Cours d'Amour ", der Höfe der Renaissance und der Salons des Vorabsolutismus gebunden war.

Während die Namen von Mlle de Scudéry oder Mme Deshoulières die ungebrochene Wirksamkeit preziöser Liebespsychologie und Weltsicht von den "Samedis« bis zum Mercure Galant verbürgen, lebte bei den »Modernes« die Frauenverehrung des Hôtel de Rambouillet und mit ihm eine neue Vorliebe für die unterhaltsame Kleinkunst auf. Hier sollte sich weibliches, aus geselliger Mündlichkeit geborenes Schreiben im 17. Jahrhundert vollenden. In der Mode des Feenmärchens, die von den Damen beherrscht wird, verdichten sich alle bisher verfolgten ständischen, geschmacklichen oder ästhetischen Zusammenhänge. Ihre Würdigung blieb sowohl die kanonbildende Literarhistorie wie auch weitgehend die Märchenforschung schuldig: die eine mit dem Apriori normklassischer Wertzumessung, das jede »Subliteratur « ausgrenzen mußte, die andere, weil hier das Urteil der Brüder Grimm gültig blieb. Diese vermißten bei Mme d'Aulnoy »etwas Natürliches und Frisches, das Einfache und Bürgerliche, das bei Perrault immer durchscheint«, und gaben seinen Märchen »bei geringerer Kunst den Vorzug«, weil sie den Stoffkern in reiner Form zu übermitteln schienen. [22]

Die Ausgrenzung dessen, was die Grimm befremdete - u.a. das Vorherrschen »weibliche[r] Eigenschaften « und damit von Liebe und Galanterie, »das überfeine und vornehme Wesen aus dem Zeitalter Ludwigs XIV.« - hatte mit der zeitgenössischen Kritik des Abbé de Villiers (1699) begonnen. Daß und in welcher Weise Frauen - als Autorinnen, fiktive Erzählerinnen und Adressatinnen der Widmung - dem Salonmärchen die Form gaben, mißbilligte er ausdrücklich. Der in der Märchenmode eher isolierte Ch. Perrault hingegen, der seine geschickten und erfolgreichen Einzelgänger - Chat Botté, Petit Poucet - aus der pikaresken Ausgangssituation herausführt [23] und die märchenhafte Wunscherfüllung im Sinne vertikaler (bürgerlicher) Integration der (männlichen) »Ellenbogenkinder« entwirft, schien bereits für de Villiers klassischer Vorbildlichkeit zu entsprechen.

Während sich jedes der Salonmärchen formelhaft zu dem neuen Erzählmodus 
der affichierten Mündlichkeit, zur kleinen Form und zur Einfachheit der »Gouvernanten und Ammen « bekannte, die bei den "gens délicats« den Maßstab der »ernsten Dinge « nicht zu fürchten brauchte, füllten gerade und nur die Damen den imaginierten Spielraum jenseits der Wirklichkeit mit einer die Regeln der Hochklassik, aber auch die der gesellschaftlichen Ordnung überschreitenden Phantasie. Wie einmal Boileau - und die »doctrine classique« seit Chapelain die Wahrheit der normierten (und normierenden) Wahrscheinlichkeit unterordnete, läßt etwa Mme de Murat nun das Wunderbare über das Wahre triumphieren. Während in Perraults Parallèle "durch den Präsidenten Simplizität und Naivität stets als Vorzug der Anciens in Feld geführt werden « [24], eben jene Werte, die dem Märchenautor selbst auch für W. Preisendanz den klassischen Kanon offen lassen, ironisiert das feminine Salonmärchen mit der spielerischen Regression in die archaische und prälogische Welt des Mittelalters und mit der grenzenlosen Phantastik des Wunderbaren, in der klassische Mythologie (»fable«) und keltische Magie (»féerie«) zusammenfinden, die Lehrlinge Boileaus.

Mehr noch als die früheren Autorinnen konnte Mme d'Aulnoy, die »reine de la féerie« (J. Barchilon), der Ächtung solcher Nachfahren gewiß sein. Die Biographie tat ein übriges, um sie der "chronique scandaleuse « ihres Jahrhunderts zuzuordnen und sie allenfalls über das spanische Lokalkolorit (Relation $d u$ voyage d'Espagne, 1691) literarisches Zeugnis ablegen zu lassen.

Die Brüder Grimm hatten den Weg zur ästhetischen Würdigung ihrer »contes de fées implizit gewiesen, die immerhin, mit denen anderer Damen, zur unmittelbaren Vorlage von Wielands »auserlesenen Feen- und Geistermärchen « wurden. Das »Wunderbare der Poesie « und damit auch das der »Feyenmärchen «, die sich »mit dem gesunden Menschenverstand oder mit der Tugend entzweyt zu haben schienen «, ist von den wenigen modernen Literarkritikern allenfalls angedeutet, nie aber mit der Entschiedenheit eines Johann Adolf Schlegel verteidigt worden. [25] J. Tucker Mitchell bemerkte eine "female dominance " in den d'Aulnoy-Märchen, doch sie unterließ die Untersuchung der entscheidenden femininen Perspektivierung der gesellschaftlichen, sozialen und psychischen Erfahrung, die diesen Texten die weibliche »Kulturfärbung« verleihen. Der Märchenforschung wiederum, die für das Volksmärchen das Fehlen jeder eigentlichen Erotik (M. Lüthi), dabei aber dessen »mögliche Entwicklung zur kunstvollen Liebesnovelle hin « (L. Röhrich) angemerkt hatte, konnte die sentimentalisierende Entfernung von der »reinen « Úberlieferung nicht zum Problem oder auch nur zum Gegenstand des Interesses werden. Allein die eingangs zitierte E. Sullerot entdeckte die Feenmärchen als Dichtung femininer Wunscherfüllung. Für sie verbirgt sich in Mme d'Aulnoys Oiseau bleu "le mythe de l'amant qui jamais ne se lasse de nous parler et de nous entendre«, und in den Märchenwundern selbst die »illusions de femmes sujets trouvant dans l'amour un pouvoir nouveau, illusions d'être fées«. [26] Diesem Gedanken galt es nachzugehen. Dabei war implizit all das aufzuarbeiten, was in der klassisch orientierten Poetik oder in der Volksmärchenforschung auf der Strecke geblieben war. Dazu gehörte der von den Grimm angedeutete, nie aber verfolgte Verweisungszusammenhang 
zwischen den d'Aulnoy-Märchen und dem proteischen Pomp von Hofballett, Oper und höfischem Fest, von Wasserspielen, Feuerwerk und den Wundern der Bühnenmaschinerien, Kulissen und Maskeraden. H.-L. Scheel und J. Rousset beschrieben am Beispiel der Thetisgrotte und des Latonabrunnens in Versailles die zirkulare Bewegung von Literatur und bildenden Künsten [27]: Mit Mlle de Scudéry und La Fontaine kehrten Skulptur und Architektur in die Dichtung zurück, von der sie ihren Ausgang genommen hatten. An den Märchen von Mme d'Aulnoy läßt sich zeigen, daß die Fülle und Farbigkeit der bewegten Bilder die Wunderwelt barocker Gesamtkunst literarisch verewigen: das Märchen vom höfischen Leben.

Die Metamorphose, die als »jeu d'esprit « bis zu Mlle de la Force (1701) nicht vergessen ist, eröffnet dem Märchen nicht allein den Horizont newer bildhafter Imagination. Die Feenwunder erlösen das junge Mädchen und das liebende Paar von einer Wirklichkeit sozialer und psychischer Bedrohung. Die wenigen und angesichts der Fülle der Texte und Vielzahl der Namen notwendig oberflächlich bleibenden Untersuchungen der »contes de fées« (M. E. Storer, T. di Scanno, J. Barchilon) lassen die Mode zum Jahrhundertende beginnen. Bereits 1667 aber war das Erzählen eines Märchens von Mlle de Scudéry als eine Spielaufgabe genannt worden. Auch dies ist damit als eines der »jeux d'esprit « zu begreifen, mit denen vorzugsweise Frauen die Feder zu führen lernten. Daß Mme d'Aulnoy preziösem Gedankengut nahestand, konnte angesichts der "préciosité «-Forschung bislang nur angedeutet werden. [28] Gerade an der ironischen Verfremdung von Motiven des Volksmärchens (Dämonenverschreibung, Opferung, Tierverwandlung), vor allem aber ihren Variationen des Psychemythos, ließ sich hier nun verfolgen, wie die Feenmärchen zur Dichtung weiblicher Wunscherfüllung werden. [29] War es K. Krüger darauf angekommen, die Quellen, Stoffkerne und Motive (Straparola, Basile und La Fontaine) im Salonmärchen der Mme d'Aulnoy auszumachen [30], so waren nunmehr die Formen höfischer aber auch femininer Umdeutung und Veränderung darzustellen und zu begründen. Dabei geriet die Auseinandersetzung der Autorin mit der zoomorphen Symbolik La Fontaines neu in den Blick und damit ihre Erwiderung auf die Bilderwelt des traditionell misogynen »bestiaire féminin «.

Auf die »Psyche«-Märchen ließ sich E. Neumanns [31] psychologische Deutung des Mythos in vollem Maße übertragen. Wie in den Binnennovellen der Scudéry-Romane durchmißt der Mann in gestufter Verwandlung und Erlösung die Landschaft des »Tendre«. Doch der »code« preziöser Erziehung gerät, wie alle von Mme d'Aulnoy anverwandelten Momente der literarischen Tradition, zusehends ins Licht ironischer Brechung. Das Mittelalter der Feen und Ritter, Zweikämpfe und Liebesorden wird in Erinnerung gerufen und im Pastiche des Altfranzösischen zugleich jeder Verbindlichkeit enthoben. Ausgegrenzt ist auch bei ihr jeder humanistische Ernst, und dies nicht aus Unvermögen, wie die Racineparodie erkennen läßt. Im Bekenntnis zum Geschmack und zur bunten Vielfalt des höfischen Barock bleibt sie in der Linie der Salonautorinnen vergangener Jahrzehnte. 
Die preziöse Liebeskasuistik, die bereits bei Mlle de Scudéry allein in utopischer Unwirklichkeit sich erfüllte, paßt sie mit spielerischer Leichtigkeit in die Märchenstoffe ein. Der »code tendre « und die Misogamie sind nicht literarische Reminiszenz, sondern konsequentes Korrelat und weibliche Replik auf die von Genealogie und Vermögensinteressen bestimmte Konvenienzehe des Ancien Régime. Anders als Mme de Lafayette oder Mlle Bernard, die mit der Verweigerung sich gegen die »désordres inouis de l'amour « abschirmen [32], entwirft Mme d'Aulnoy parallel zur Dämonisierung der Heirat - der säkularisierten Opferung der jungen Psyche an die verfügenden sozialen Instanzen - die im Schutze der Feen begründete Liebeserfüllung.

Was die Grimm befremdet hatte - die aristokratische und feminine Färbung -, versprach aus umgekehrter Sicht eine neue Dimension märchenhafter Glücksdichtung zu eröffenen. Empfahl sich Perrault der Erwartung bürgerlicher Wunscherfüllung, die in der vertikalen Linie des sozialen Aufstiegs, aber auch im Frauenideal der Griseldis sich niederschlug, so wurde die Comtesse d'Aulnoy zur Anwältin ihrer Prinzessinnen, für die die Märchenwunder sich allein auf der Ebene des liebenden Paars vollziehen sollten. Perraults ratlose Frage nach dem Sinn des ihm unergründlichen Psyche-Mythos -

Je sais bien que Psyché signifie l'Ame; mais je ne comprends point ce qu'il faut entendre par l'Amour qui est amoureux de Psyché, c'est-à-dire de l'âme [...] -

findet bei Mme d'Aulnoy ihre - kaum vernommene - Antwort. Evelyne Sullerot wiederum gab jüngst die Frage an Perrault und die Tradition der Griseldisnovelle zurück. [33]

Barocke Synästhesie und lebendiges Mittelalter, »jeux d'esprit«, »divertissement « und der »code « preziösen Liebens stellen Mme d'Aulnoy in die unmittelbare Nachfolge der Salonautorinnen vor ihr und vor allem von Mlle de Scudéry. Metamorphose und Travestie - literarisches Spiel im Hôtel de Rambouillet und gelebte Wirklichkeit bei den »Amazones de la Fronde « - stiften in der produktiven Aufnahme bei der "modernen " Autorin einen Horizont psychischer und sentimentaler Uneindeutigkit. M. Lüthis Anmerkung, daß die gleitenden Übergänge von Sein und Schein zu den fundamentalen Zügen des Volksmärchens zum einen, der barocken Kunst und Lebensformen zum anderen gehören [34], ließ sich an ihren Salonmärchen bestätigen. Mit den Schäfer- und Inselidyllen schließlich greift sie das von Mlle de Montpensier und Mme de Motteville imaginierte »weibliche« Arkadien ebenso auf wie die Kritik am höfischen Absolutismus bei Mlle de Scudéry. Wie diese versetzt sie die Könige ihrer Märchen in eine Welt der Unaufrichtigkeit und falschen Freunde, stellt ihre Macht als Folge gewissenloser Usurpation und sie selbst als identitätslos und schwach gegenüber Intriganten und herrschsüchtigen Frauen dar. Mit dem Schäferkönig und Philosophen Sublime entwirft sie die Utopie politischer Idealität, die die erotische Erlösung der benachteiligten weiblichen »Ellenbogenkinder" durch den »prince charmant « auf höherer Ebene vollendet. Auch für sie ist der »code tendre " ein nicht allein liebespsychologisches Ideal, sondern ein weiterreichender morali- 
scher Anspruch, den sie nach der Schwere des barocken Romans und der komplizierten Chiffrierung bei Mlle de Scudéry im heiteren Spiel der Phantasie und der Anmut des Rokoko mit den Feenwundern sich erfüllen läßt. [35] Nach dem Selbstportrait der Hocharistokratinnen, dem Mlle de Montpensier die Richtung weist, den Vorbehalten der Frauen gegenüber La Rochefoucauld, die in Urteil und Vermittlung von Mme de Sablé wirksam werden, steht Mme d'Aulnoy in der Mitte einer weiblichen Gruppe, der der geschlossene Schutz- und Fluchtraum des Salons die Freiheit des Schreibens, aber auch die der unangefochtenen Selbstreflexion und Wunschentwürfe eröffnet. Die alte Selbstverständlichkeit adliger Frauenverehrung, auf die der bedrängte Schwertadel sich um die Jahrhundertmitte als einen der ihn traditionell auszeichnenden Werte besann, sicherte den einzelnen und den vielen eine - fortan verlorene - Aufmerksamkeit für die weiblichen Entwürfe eines idealen Menschen- und Weltbildes. 